\title{
Gallium-68 perfusion positron emission tomography/computed tomography to assess pulmonary function in lung cancer patients undergoing surgery
}

Pierre-Yves Le Roux ${ }^{1,2,8^{*}+}$, Tracy L. Leong ${ }^{3 \dagger}$, Stephen A Barnett ${ }^{3,4,5}$, Rodney J. Hicks ${ }^{1,3}$, Jason Callahan ${ }^{1}$, Peter Eu ${ }^{1}$, Renee Manser ${ }^{6,7}$ and Michael S. Hofman ${ }^{1,3^{*}}$

\begin{abstract}
Background: Pre-operative evaluation of lung cancer patients relies on calculation of predicted post-operative (PPO) lung function based on split lung function testing. Pulmonary perfusion (Q) PET/CT can now be performed by substituting Technetium-99 m labeling of macroaggregated albumin (MAA) with Gallium-68. This study compares Q PET/CT with current recommended methods of pre-operative lung function assessment.

Methods: Twenty-two patients planned for curative surgical resection (mean FEV1 77 \%, SD 21 \%; mean DLCO $66 \%$, SD $17 \%$ predicted) underwent pre-operative Q PET/CT. Sixteen patients also underwent conventional lung scintigraphy. Lobar and lung split PPO lung function were calculated using Q PET/CT and current recommended methods, i.e. calculation based on anatomical segments for lobar function, and conventional perfusion scan for pneumonectomy. Bland-Altman statistics were used to calculate agreement between methods for PPO FEV1 and PPO DLCO.

Results: While mean split lobar functions were comparable, there was variation on an individual level between Q PET/CT and the anatomical method, with absolute difference over $5 \%$ and $10 \%$ in $37 \%$ and $11 \%$ of patients, respectively. For lobectomy the mean difference in PPO FEV1 was-1.2, but limits of agreement were-10 to $8.1 \%$. For DLCO, values were- $1.1 \%$ and -9.7 to $7.5 \%$, respectively. For pneumonectomy, PPO FEV1 values were-0.4 and -5.9 to $5.1 \%$. For DLCO, values were $0.3 \%$ and -5.1 to $4.6 \%$.

Conclusions: While anatomic estimation provides "fixed" results, split lobar functions computed with Q PET/CT vary widely, reflecting the intra and inter-individual variability of regional lung function. Further studies to assess the role of Q PET/CT in predicting peri-operative risk in lung cancer patients planned for lobectomy are warranted.
\end{abstract}

Keywords: PET/CT, Perfusion, Gallium-68, Surgery, Lung cancer

\section{Background}

Lung cancer is the leading cause of cancer-related mortality worldwide [1]. In individuals with stage I and II non-small cell lung cancer, surgery is the treatment of choice if the tumour is considered resectable and the patient is considered fit for surgery [2]. Despite

\footnotetext{
*Correspondence: pierre-yves.leroux@chu-brest.fr; michael.hofman@ petermac.org

${ }^{+}$Equal contributors

'Division of Radiation Oncology and Cancer Imaging, Peter MacCallum Cancer Centre, St. Andrews Place, East Melbourne, VIC 3002, Australia Full list of author information is available at the end of the article
}

refinements in lung resection techniques, post-operative morbidity and mortality are significant and only 20$25 \%$ of patients will eventually undergo surgery [3]. Most patients with lung cancer are former or current smokers, which increases operative risk, particularly due to chronic obstructive pulmonary disease (COPD). The dilemma then arises of whether to perform potentially life saving surgery in a patient who has an increased risk of operative mortality or of significant post-operative dyspnoea. Therefore, accurate evaluation of preoperative lung function is imperative to estimate the risk 
of both short and long-term post-operative adverse events, and to select patients who will derive maximum benefit with minimal risk from surgery [3].

Current guidelines recommend a series of investigations to risk stratify patients [4-6]. Initial tests include measurement of the forced expiratory volume in $1 \mathrm{sec}-$ ond (FEV1) and diffusion capacity of the lung for carbon monoxide (DLCO). However, these tests alone are limited because they do not take into account the high degree of inter-patient variability including regional heterogeneity of any underlying lung disease, the extent of lung to be resected, and the contribution of the portion of lung to be removed to overall lung function. Accordingly, split lung function testing is used in conjunction with FEV1 and DLCO to assess the functional contribution of the lung to be resected and to calculate a predicted post-operative (PPO) value of lung function. The American College of Chest Physicians (ACCP) guidelines recommend that both FEV1 and DLCO be measured and that both PPO FEV1 and PPO DLCO are calculated in all patients with lung cancer being considered for surgery [6]. To compute PPO values, guidelines recommend the use of conventional perfusion scintigraphy using macroaggregated albumin (MAA) labelled with Technetium-99 m ( $\left.{ }^{99 \mathrm{~m}} \mathrm{Tc}\right)$ before pneumonectomy or an anatomic method based on counting the number of functional segments to be removed before lobectomy [6].

Our group has demonstrated the feasibility of transitioning from conventional single photon techniques to positron emission tomography (PET) technology for lung scintigraphy [7]. ${ }^{99 \mathrm{~m}} \mathrm{Tc}$ can be substituted by Gallium-68 $\left({ }^{68} \mathrm{Ga}\right)$, a positron-emitting radionuclide, to label MAA, which are trapped in the lung capillaries so that local concentration is related to the regional pulmonary blood flow. The regional distribution of perfusion within the lungs is then possible using PET technology. This offers a unique opportunity to improve the diagnostic performance of lung perfusion imaging, due to the higher sensitivity, spatial resolution, speed of acquisition and, most importantly, quantitative capability of PET in comparison to conventional scintigraphy [8]. In a recent study, we showed a high degree of correlation between ventilation-perfusion PET/CT functional lungs volumes and pulmonary function tests (PFTs) parameters [9], suggesting significant potential in management of patients with pulmonary disease. We have also explored this technology for individualising radiotherapy treatment plans $[10,11]$ and assessing radiation injury to lungs $[10,12]$.

In order to assess the potential utility of this new technology for pre-operative assessment of lung cancer patients, we aimed to compare the information provided by perfusion $(\mathrm{Q}) \mathrm{PET} / \mathrm{CT}$ imaging with that of current recommended methods, when assessing split lung function and computing PPO values of lung function in lung cancer patients being considered for surgery.

\section{Methods \\ Patients}

In this retrospective series, patients referred to our PET centre for Q PET/CT imaging as part of their preoperative evaluation for lung surgery by a single surgeon were identified between 2013 and 2014. Patients with biopsy proven lung malignancy were planned for surgery with curative intent based on exclusion of distant metastatic disease by FDG PET/CT. Patients with clinically suspected lung malignancy were planned for intraoperative frozen section to confirm presumed malignancy prior to resection with curative intent. All patients underwent PFTs and gated perfusion PET/CT as part of pretreatment evaluation. 16 patients also underwent planar lung scintigraphy using ${ }^{99 \mathrm{~m}}$ Tc-MAA. Three patients were 'salvage cases' ie they had undergone chemo radiation with curative intent months prior and had failed locally. Out of the 22 patients, 13 underwent a lobectomy, 4 a segmentomy, 1 a pneumonectomy and 4 patients did not have curative surgery, respectively. The study was performed in accordance with the Declaration of Helsinki and was approved by the institutional ethics committee (Number 13/152).

\section{Pulmonary function tests}

Spirometry was performed in accordance with the joint European Respiratory Society (ERS) and American Thoracic Society (ATS) clinical practice guidelines [13, 14]. Post bronchodilator FEV1 was expressed as an absolute value and a percentage of predicted and DLCO as a percentage of predicted.

\section{Q PET/CT protocol}

All patients underwent a respiratory-gated (4D) PET-CT lung perfusion scan using a procedure that we have previously described [15]. Patients were imaged on a GE Discovery 690 PET/CT scanner (GE Medical Systems Milwaukee, WI, USA) after injection of approximately $50 \mathrm{MBq}$ of ${ }^{68} \mathrm{Ga}-\mathrm{MAA}$ [7]. The perfusion PET was acquired as a two-bed acquisition encompassing the apex to base of both lungs planned by a scout CT. Each bed position was acquired for $5 \mathrm{~min}$.

\section{Split lung function calculation \\ Conventional methods}

As a reference standard, lobar and lung split function were computed according to current recommended methods, using an anatomic estimation before lobectomy and by a conventional planar perfusion scan before pneumonectomy [6]. 
For lobar split function assessment, the following equation was used:

\section{Relative function $=$ Number of functional or unobstructed lung segments in the lobe of interest / total number of functional or unobstructed lung segments.}

The total number of segments for both lungs was 19 (10 in the right lung: 3 in the upper, 2 in the middle, 5 in the lower; and 9 in the left lung: 3 in the upper division, 2 in the lingula and 4 in the lower) [16].

For lung split function assessment, conventional planar perfusion scintigraphy was used as follow:

$$
\begin{aligned}
\text { Relative function }= & \text { perfusion in the lung of interest } / \\
& \text { total lung perfusion }
\end{aligned}
$$

\section{Q PET/CT}

Lobes were delineated on CT images using MIMimage analysis software (MIM 5.4.4; MIMSoftware, Cleveland, $\mathrm{OH}, \mathrm{USA})$. In the left upper lobe, the lingula and the left upper division were delineated. Segmentation was subsequently applied to the PET images and the following equation was used to compute split lung function for each lobe and lung:

$$
\begin{aligned}
\text { Relative function }= & \text { perfusion in the region of interest / } \\
& \text { total lung perfusion }
\end{aligned}
$$

\section{PPO lung function calculation}

PPO FEV1 as an absolute value (in litres) and a percent predicted, and PPO DLCO as a percent predicted, were computed for all 22 patients for 2 scenarios- 1 assuming each would undergo pneumonectomy for the index lesion and for this scenario we compared Q PET/CT with planar VQ (in accordance with current guidelines) and in the second scenario we assumed each patient would undergo lobectomy for the index lesion and compared Q PET/CT with the anatomical method for calculating post op lung function (as is recommended in current guidelines).

PPO values were calculated using the following equations:

$$
\begin{aligned}
\text { PPO FEV } 1= & \text { pre-operative FEV } 1 \times \text { fraction of total } \\
& \text { function to be removed } \\
P P O D L C O= & \text { pre-operative DLCO } x \text { fraction of } \\
& \text { total function to be removed }
\end{aligned}
$$

\section{Statistical analysis}

All statistical tests were carried out using GraphPad Prism 5 (La Jolla, CA, USA). The mean, standard deviation, and ranges were computed for all split lung function and PPO PFTs values. Limits of agreement between PPO PFTs values were analysed by means of Bland-Altman analysis.

\section{Results and discussion}

Twenty-two patients (11 males, 11 females; mean age 67 years, range $38-82$ years) were analysed. The mean pre-operative FEV1 was $2.04 \mathrm{~L}$ (SD: $0.65 \mathrm{~L}$; range: 1.00 $3.26 \mathrm{~L}$ ) and the mean pre-operative percentage of predicted FEV1 was 77 \% (SD: 21 \%; range: 33-123 \%). The mean pre-operative percentage of predicted DLCO was 66 \% (SD: $17 \%$; range: 39-110 \%). Primary lesion was located in the right upper lobe in 9 patients, the right middle lobe in 2 , the right lower lobe in 4 , the left upper division in 6 , and the left lower lobe in 1 patient.

\section{Split lung function}

Mean of split lung functions computed with Q PET/CT and the reference methods were not statically different. However, standard deviation and range of split lobar function were much wider using Q PET/CT rather than the anatomical method (See Table 1 and Fig. 1). The absolute difference in lobar split function between Q PET/ $\mathrm{CT}$ and the anatomic method was greater than $5 \%$ of total lung function in 49 of 132 lobes (37\%), and greater than $10 \%$ in 15 of 132 of lobes (11.4\%). The absolute difference in lung split function between Q PET/CT and planar perfusion scan was greater than $5 \%$ of total lung

\begin{tabular}{|c|c|c|c|c|c|c|}
\hline & \multicolumn{3}{|c|}{ Anatomic estimation } & \multicolumn{3}{|c|}{ Q PET/CT } \\
\hline & Mean & sd & Range & Mean & $\mathrm{sd}$ & Range \\
\hline RUL & 15 & 3 & $0-16$ & 15 & 8 & $1-31$ \\
\hline RML & 11 & 0 & $11-13$ & 9 & 4 & $3-17$ \\
\hline RLL & 27 & 1 & $26-31$ & 27 & 6 & $14-37$ \\
\hline LUD & 16 & 1 & $16-19$ & 16 & 6 & $5-25$ \\
\hline Lingula & 11 & 0 & $11-13$ & 7 & 2 & $5-12$ \\
\hline LLL & 21 & 1 & $21-25$ & 26 & 11 & $9-48$ \\
\hline \multirow[t]{3}{*}{ Index lobe } & 17 & 6 & $0-26$ & 15 & 7 & $1-37$ \\
\hline & \multicolumn{3}{|c|}{ Planar perfusion scan } & \multicolumn{3}{|c|}{ Q PET/CT } \\
\hline & Mean & sd & Range & Mean & sd & Range \\
\hline $\mathrm{RL}$ & 49 & 10 & $29-59$ & 51 & 11 & $23-54$ \\
\hline $\mathrm{LL}$ & 51 & 10 & $41-71$ & 49 & 11 & $36-77$ \\
\hline Index lung & 46 & 9 & $29-59$ & 45 & 11 & $23-61$ \\
\hline
\end{tabular}
function in $19 \%$ of lungs but never more than $10 \%$. Figure 2 shows an example of different lobar split function using Q PET/CT or the anatomic estimation.

Table 1 Comparison of split function computed with Q PET/CT and the recommended methods (anatomic estimation for lobar split function, conventional perfusion scan for lung split function) for all lobes and lungs regardless of index lesion

Results are expressed as percentage of total lung function 

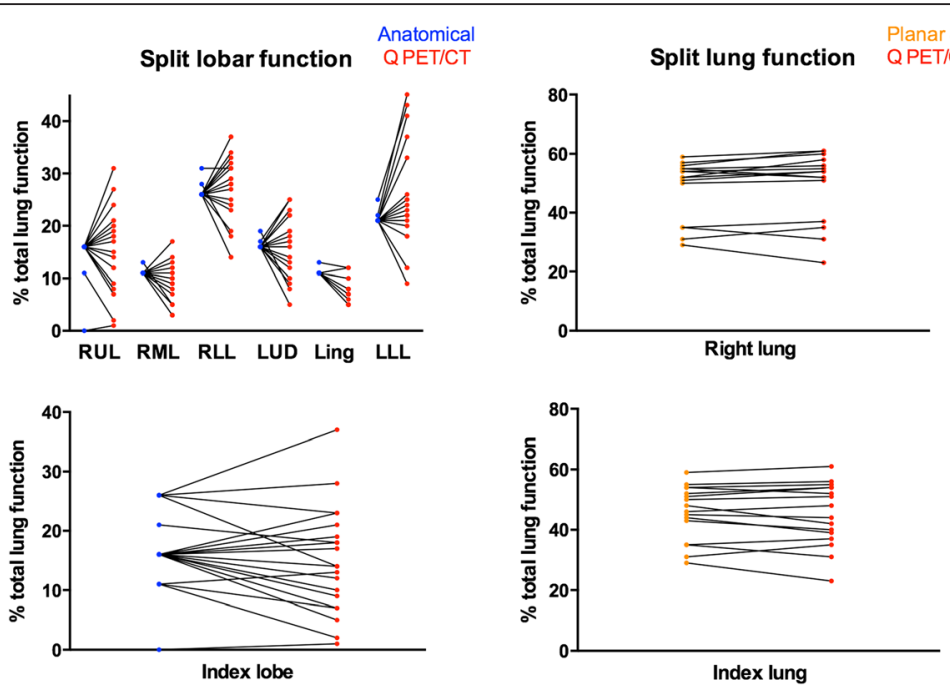

Fig. 1 Paired split lung function using Q PET/CT and the recommended methods, i.e. the anatomical method for split lobar function, and planar scintigraphy for relative lung function

\section{PPO lung function after lobectomy}

The mean, standard deviation and range of Predicted post-operative \% predicted FEV1, absolute FEV1 and DLCO, as calculated by the anatomical method or $\mathrm{Q}$ $\mathrm{PET} / \mathrm{CT}$ are presented in Table 2. The mean of the difference and the limits of agreement between PPO as \% predicted FEV1 and \% predicted DLCO are shown in Fig. 3.

\section{PPO lung function after pneumonectomy}

The mean, standard deviation and range of PPO \% predicted FEV1, FEV1 and \% predicted DLCO using the planar scintigraphy or Q PET/CT are presented in Table 3. The mean of the difference and the limits of agreement between $\mathrm{PPO}$ as \% predicted FEV1 and \% predicted DLCO are shown in Fig. 3.

\section{Discussion}

In the present study, we found that lobar lung split functions calculated by Q PET/CT differ from that estimated with the current recommended methodology [6]. While anatomic estimation provides "fixed" results, relative lobar functions vary widely using Q PET/CT, consistent

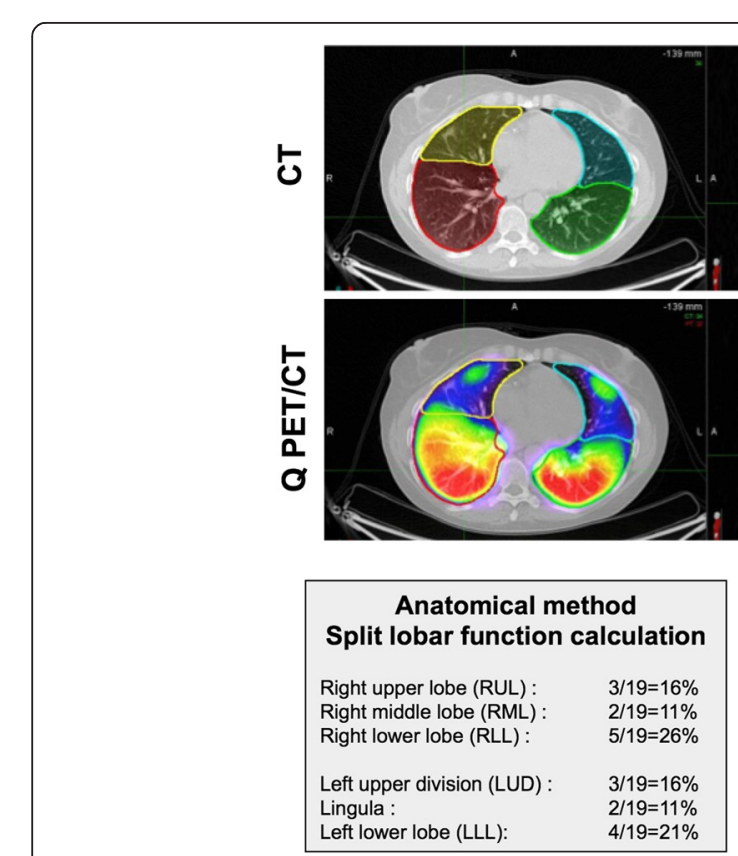

Fig. 2 Example of discordant lobar split function distribution

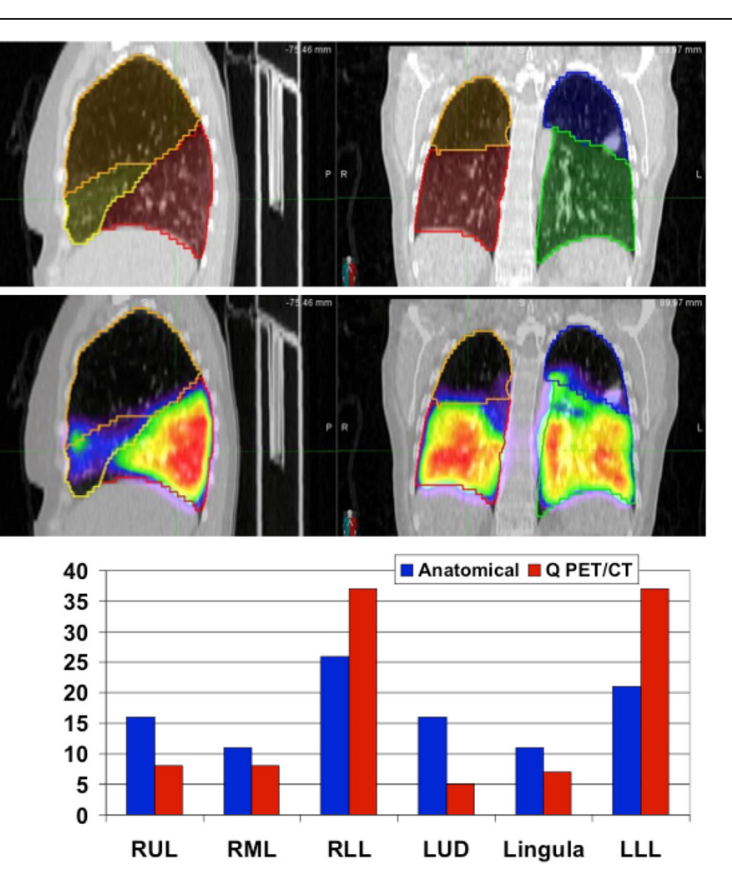


Table 2 PPO PFTs values after lobectomy of the index lobe

\begin{tabular}{|c|c|c|c|c|c|c|}
\hline & \multicolumn{3}{|c|}{ Anatomical } & \multicolumn{3}{|c|}{ Q PET/CT } \\
\hline & Mean & $\mathrm{sd}$ & Range & Mean & $\mathrm{sd}$ & Range \\
\hline FEV1 \% pred & 64 & 19 & $26-110$ & 65 & 19 & $27-107$ \\
\hline FEV1 L & 1.69 & 0.52 & $0.79-2.65$ & 1.72 & 0.54 & $0.82-2.81$ \\
\hline DLCO \% pred & 55 & 15 & $33-93$ & 56 & 15 & $35-90$ \\
\hline
\end{tabular}

with known inter-individual variability of regional lung function. The impact of $\mathrm{Q} P E T / C T$ when calculating PPO lung function was less marked, but not trivial clinically, in this small series including patients without significant lung function impairment. On the other hand, Q PET/CT does not seem to provide major differences as compared with conventional planar scintigraphy in patients being assessed for pneumonectomy. This is not entirely unexpected since both reflect the ratio of perfusion to the left and right lungs.

We compared lobar split function computed with Q $\mathrm{PET} / \mathrm{CT}$ and the current recommended method, i.e. an anatomical approach based on counting the number of functional segments to be removed [6]. While mean lobar split functions were very close with both methods, standard deviations and ranges were much wider using Q PET/CT, with lobar relative function being either higher or lower than that predicted with the anatomic method. Overall, absolute difference in lobar split function between both methods was greater than $5 \%$ of total lung function in $37.1 \%$ lobes and greater than $10 \%$ in $11.4 \%$ of lobes. Given the heterogeneity of regional lung function, especially in patients with COPD [17], these results are likely to be more representative of the interindividual variability of regional lung function as compared with the fairly "fixed" results provided by the anatomical method.

The question then arises regarding the impact of such results when estimating the risk of adverse surgical events, i.e. when calculating PPO FEV1 and DLCO. In the present study, the limits of agreement between PPO values of lung function predicted from $\mathrm{Q} P E T / C T$ and the anatomical method were up to $10 \%$ (PPO FEV1:-10-8.1 \% 1; PPO DLCO:-9.7-7.5 \%). These limits of agreement appear large and clinically significant in the setting of a pre-operative workup of a lung cancer patients being considered for surgery. In a study of 1,428 subjects undergoing lung resection, Alam et al. found a $10 \%$ increase in the risk of complications for every $5 \%$ decrement in PPO lung function [18]. In the ACCP guidelines for physiologic evaluation of lung cancer patients before surgery, a functional algorithm based on measurement of PPO FEV1 and PPO DLCO in all patients is proposed. In particular, a cut-off value of $60 \%$ is proposed for both PPO FEV1 and PPO DLCO to select patients with a low risk for surgery. If one parameter

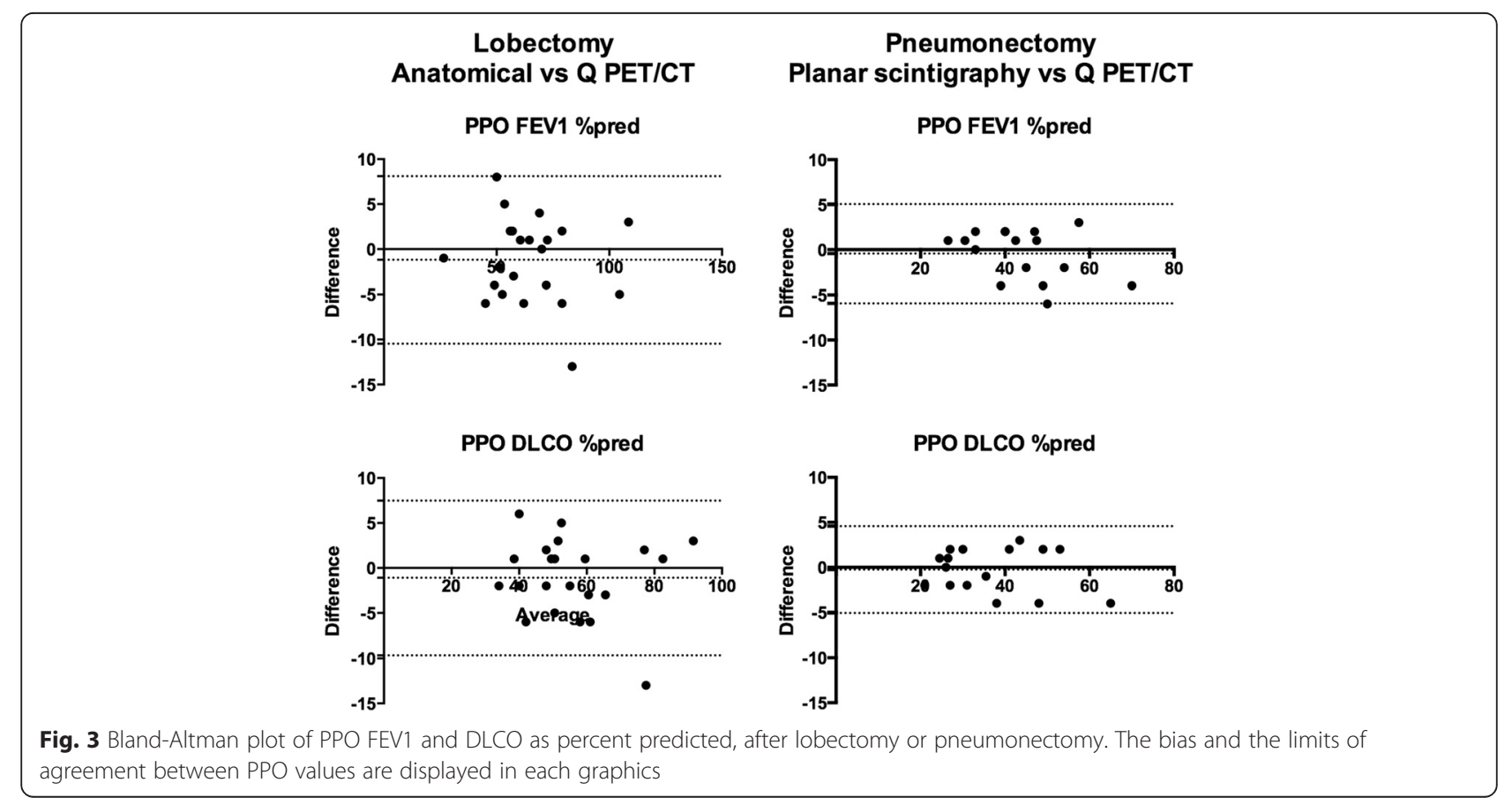


Table 3 PPO PFTs values after pneumonectomy of the index lung

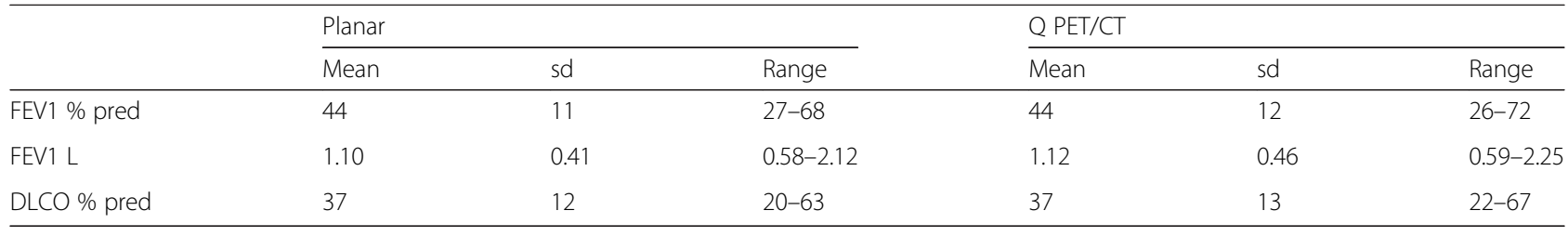

is lower than $60 \%$, further testing is recommended. In our series of 22 patients, 3 would have had a different management using Q PET/CT rather than the anatomical method when computing PPO values. In addition, using the historical $40 \%$ cut-off to select patients suitable for surgery with an acceptable clinical outcome, decision-making would have been different in 2 additional patients. Nevertheless, there were no patients with PPO FEV1 or PPO DLCO lower than $30 \%$, which has been recently described as a more adapted cut-off $[6,19]$.

When simulating a pneumonectomy of the index lung, the impact of transitioning from conventional planar scintigraphy to PET technology was less convincing. Mean, standard deviation and graphical analysis of split lung functions demonstrate close results with both methods. Limits of agreement were smaller (PPO FEV:-5.9-5.1 \% 1; PPO DLCO:-5.1-4.6 \%) as compared with a lobectomy. However, both lung and lobar split lung function calculation may be advantageous in patients with borderline lung function to compare the post-operative risk of both pneumonectomy and lobectomy to aide surgical decision making in the event that intraoperative findings preclude safe oncological lobectomy. In that setting, Q PET/CT may offer the advantage of providing an accurate assessment of the risk of both types of surgery in a single test.

Perfusion PET/CT imaging represents a promising alternative to current methods owing to several advantages. The acquisition time is around six minutes less than for conventional planar scintigraphy using a dualdetector gamma camera but provides fully tomographic images of higher resolution. SPECT/CT can provide tomographic images but has a significantly longer acquisition time and provides lower resolution. As with conventional scintigraphy, there are no known contraindications or acute side effects (allergy) associated with the radiotracers. The effective radiation dose of the scan is low, approximately $1 \mathrm{mSv}$ for the PET acquisition plus an additional 1-2 $\mathrm{mSv}$ for the low dose CT component. In addition, the number of particles typically used for a fresh ${ }^{68} \mathrm{Ga}$ MAA administration is approximately half of that used for a fresh ${ }^{99 m}$ Tc-MAA administration, which may be an advantage of VQ PET as compared with VQ SPECT in patients with pulmonary hypertension. In our institution, there is no significant increase in cost or processing as regards Ga68-MAA labelling but this may vary according to local expertise and facilities. Finally, ${ }^{68} \mathrm{Ga}$ is produced by an on-site generator enabling ondemand availability similar to ${ }^{99 \mathrm{~m}} \mathrm{Tc}$, but with a longer shelf-life of $9-12$ months versus $1-2$ weeks for ${ }^{99} \mathrm{~m}$ Tc generator. The ${ }^{68} \mathrm{Ga}$ generator is increasingly available owing to its use for neuroendocrine [20] and prostate cancer imaging. With PET/CT and ${ }^{68} \mathrm{Ga}$ becoming increasingly available, we envisage that widespread adoption of V/Q PET/CT could become a reality as part of a more general more of diagnostic nuclear medicine towards PET/CT technology [8].

This study has several limitations. First, PPO lung functions were not correlated with actual post-operative lung function. Nevertheless, there is evidence than PPO values are prognostic factors for short and long-term postoperative risk rather than accurate predictors of post-operative lung function [21]. In particular, many studies have reported an improvement in pulmonary function after lung surgery in some patients with COPD in keeping with a lung volume reduction effect [22]. On the other hand, the risk of post-operative complications has been linked to PPO lung function [18]. In this small series, we did not assess the prognostic value of PPO PFT values computed using Q PET/CT. As a first necessary step, we showed that this new technology provides different information as compared with current recommended methods, which justify, from our point of view, further studies whose objective will be to compare the prognostic value of methodologies in terms of postoperative morbidity and mortality. Second, we did not compare Q PET/CT results to other modalities such as V/Q SPECT/CT [23], quantitative CT [24] or MRI [25], which have also been proposed to predict post-operative lung function. However, we compared Q PET/CT to the currently recommended methodologies, which are likely to be the most commonly used method in clinical practice. Third, this study was limited to a small series of patients and included some patients with non-impaired lung function. Again, this was performed in keeping with clinical guidelines. Nevertheless, it is likely that the usefulness of such a modality that aims at providing a more personalized approach would be greater in patients with borderline lung function. Finally, for a variety of reasons including patient preference and logistic considerations, only approximately $1 / 3$ of patients assessed for resection 
during the inclusion period underwent $\mathrm{Q}$ PET/CT assessment. A selection bias is therefore a possibility. However, this was a heterogeneous group of patients, likely broadly reflecting the surgeons' standard practice.

\section{Conclusions}

To the best of our knowledge, this study is the first assessing Q PET/CT to compute split lung function and predict $\mathrm{PPO}$ lung function in lung cancer surgery patients. In the pre-therapeutic work up of patients undergoing lobectomy, Q PET/CT provides different results compared to the anatomical estimation, with a wider range of results that may be more representative of the inter-individual variability of regional lung function. Further larger studies are now needed to assess if $\mathrm{Q}$ $\mathrm{PET} / \mathrm{CT}$ allows better prediction of short and long-term outcome and may influence management of lung cancer patients undergoing surgery.

\section{Abbreviations}

COPD, chronic obstructive pulmonary disease; DLCO, diffusion capacity of the lung for carbon monoxide; FEV1, forced expiratory volume in 1 second; MAA, macroaggregated albumin; PFTs, pulmonary function tests; PPO, Predicted post-operative; Q PET/CT, Perfusion Positron Emission Tomography/Computed Tomography; SD, Standard deviation

\section{Acknowledgements}

Not applicable.

\section{Funding}

Not applicable.

\section{Availability of data and material}

Not applicable.

\section{Competing interests}

The authors declare that they have no competing interests.

\section{Consent for publications}

Not applicable.

\section{Authors' contributions}

$P Y L R, T L, S B, R H, R M, M H$ contributed to designing the study. TL, SB, RM contributed to patient recruitment. $\mathrm{RH}, \mathrm{JC}, \mathrm{PE}, \mathrm{MH}$ contributed to managing imaging procedures. PYLR, TL, SB, RH, RM, MH contributed to analysing the data. All authors contributed to writing the manuscript. All authors read and approved the final manuscript.

\section{Authors' information}

Not applicable.

\section{Ethics approval and consent to participate}

The study was performed in accordance with the Declaration of Helsinki and was approved by the Peter MacCallum Cancer Institute ethics committee (Number 13/152). Requirement for written consent was waived by the Institutional Review Board.

\section{Author details}

'Division of Radiation Oncology and Cancer Imaging, Peter MacCallum Cancer Centre, St. Andrews Place, East Melbourne, VIC 3002, Australia. ${ }^{2}$ Nuclear Medicine department, Brest University Hospital, EA3878 (GETBO) IFR 148, Brest, France. ${ }^{3}$ The University of Melbourne, Parkville, Australia. ${ }^{4}$ Department of Surgery, Austin Health, Heidelberg, Australia. ${ }^{5}$ Department of Surgery, Royal Melbourne Hospital and Peter MacCallum Cancer Centre, St. Andrews Place, East Melbourne, VIC 3002, Australia. ${ }^{6}$ Department of Cancer Medicine, Peter MacCallum Cancer Centre, St. Andrews Place, East
Melbourne, VIC 3002, Australia. 'Department of Respiratory Medicine, Royal Melbourne Hospital, Grattan Street, Parkville, VIC, Australia. ${ }^{8}$ Service de médecine nucléaire, CHRU de Brest, 29609 Brest Cedex, France.

Received: 1 March 2016 Accepted: 6 August 2016

Published online: 20 August 2016

\section{References}

1. Jemal A, Bray F, Center MM, Ferlay J, Ward E, Forman D. Global cancer statistics. CA Cancer I Clin. 2011;61:69-90.

2. Howington JA, Blum MG, Chang AC, Balekian AA, Murthy SC. Treatment of stage I and II non-small cell lung cancer: Diagnosis and management of lung cancer, 3rd ed: American College of Chest Physicians evidence-based clinical practice guidelines. Chest. 2013;143:e278S-313S.

3. Datta $\mathrm{D}$, Lahiri B. Preoperative evaluation of patients undergoing lung resection surgery. Chest. 2003;123:2096-103.

4. Brunelli A, Charloux A, Bolliger CT, Rocco G, Sculier JP, Varela G, et al. ERS/ ESTS clinical guidelines on fitness for radical therapy in lung cancer patients (surgery and chemo-radiotherapy). Eur Respir J. 2009;34:17-41.

5. British Thoracic S, Society of Cardiothoracic Surgeons of Great B, Ireland Working P. BTS guidelines: guidelines on the selection of patients with lung cancer for surgery. Thorax. 2001;56:89-108.

6. Brunelli A, Kim AW, Berger Kl, Addrizzo-Harris DJ. Physiologic evaluation of the patient with lung cancer being considered for resectional surgery: Diagnosis and management of lung cancer, 3rd ed: American College of Chest Physicians evidence-based clinical practice guidelines. Chest. 2013; 143:e1665-90S

7. Hofman MS, Beauregard JM, Barber TW, Neels OC, Eu P, Hicks RJ. 68Ga PET/ CT ventilation-perfusion imaging for pulmonary embolism: a pilot study with comparison to conventional scintigraphy. J Nucl Med. 2011;52:1513-9.

8. Hicks RJ, Hofman MS. Is there still a role for SPECT-CT in oncology in the PET-CT era? Nat Rev Clin Oncol. 2012;9:712-20.

9. Le Roux PY, Siva S, Steinfort DP, Callahan J, Eu P, Irving LB, et al. Correlation of 68Gallium ventilation-perfusion PET/CT with pulmonary function test indices for assessing lung function. J Nucl Med. 2015.

10. Hardcastle N, Hofman MS, Hicks RJ, Callahan J, Kron T, MacManus MP, et al. Accuracy and Utility of Deformable Image Registration in (68) Ga 4D PET/CT Assessment of Pulmonary Perfusion Changes During and After Lung Radiation Therapy. Int J Radiat Oncol Biol Phys. 2015;93:196-204.

11. Siva S, Thomas R, Callahan J, Hardcastle N, Pham D, Kron T, et al. Highresolution pulmonary ventilation and perfusion PET/CT allows for functionally adapted intensity modulated radiotherapy in lung cancer. Radiother Oncol. 2015;115:157-62.

12. Siva S, Hardcastle N, Kron T, Bressel M, Callahan J, MacManus MP, et al. Ventilation/Perfusion Positron Emission Tomography-Based Assessment of Radiation Injury to Lung. Int J Radiat Oncol Biol Phys. 2015.

13. Crapo RO, Casaburi R, Coates AL, et al. Standardization of Spirometry, 1994 Update. American Thoracic Society. Am J Respir Crit Care Med. 1995; 152:1107-36.

14. Macintyre N, Crapo RO, Viegi G, Johnson DC, van der Grinten CP, Brusasco $\mathrm{V}$, et al. Standardisation of the single-breath determination of carbon monoxide uptake in the lung. Eur Respir J. 2005:26:720-35.

15. Callahan J, Hofman MS, Siva S, Kron T, Schneider ME, Binns D, et al. Highresolution imaging of pulmonary ventilation and perfusion with 68Ga-VQ respiratory gated (4-D) PET/CT. Eur J Nucl Med Mol Imaging. 2014;41:343-9.

16. Bolliger CT, Guckel C, Engel H, Stohr S, Wyser CP, Schoetzau A, et al. Prediction of functional reserves after lung resection: comparison between quantitative computed tomography, scintigraphy, and anatomy. Respiration. 2002;69:482-9

17. Agusti A, Sobradillo P, Celli B. Addressing the complexity of chronic obstructive pulmonary disease: from phenotypes and biomarkers to scalefree networks, systems biology, and P4 medicine. Am J Respir Crit Care Med. 2011;183:1129-37.

18. Alam N, Park BJ, Wilton A, Seshan VE, Bains MS, Downey RJ, et al. Incidence and risk factors for lung injury after lung cancer resection. Ann Thorac Surg. 2007;84:1085-91. discussion 91

19. Puente-Maestu L, Villar F, Gonzalez-Casurran G, Moreno N, Martinez Y, Simon C, et al. Early and long-term validation of an algorithm assessing fitness for surgery in patients with postoperative FEV (1) and diffusing capacity of the lung for carbon monoxide $<40 \%$. Chest. 2011;139:1430-8. 
20. Hofman MS, Kong G, Neels OC, Eu P, Hong E, Hicks RJ. High management impact of Ga-68 DOTATATE (GaTate) PET/CT for imaging neuroendocrine and other somatostatin expressing tumours. J Med Imaging Radiat Oncol. 2012:56:40-7.

21. Barnett SA, Rusch WW, Zheng J, Park BJ, Rizk NP, Plourde G, et al. Contemporary results of surgical resection of non-small cell lung cancer after induction therapy: a review of 549 consecutive cases. J Thorac Oncol. 2011;6:1530-6.

22. Brunelli A, Xiume F, Refai M, Salati M, Marasco R, Sciarra V, et al. Evaluation of expiratory volume, diffusion capacity, and exercise tolerance following major lung resection: a prospective follow-up analysis. Chest. 2007;131:141-7.

23. Suga K, Kawakami Y, Zaki M, Yamashita T, Shimizu K, Matsunaga N. Clinical utility of co-registered respiratory-gated (99 m) Tc-Technegas/MAA SPECT$\mathrm{CT}$ images in the assessment of regional lung functional impairment in patients with lung cancer. Eur J Nucl Med Mol Imaging. 2004:31:1280-90.

24. Yoshimoto K, Nomori H, Mori T, Kobayashi H, Ohba Y, Shibata H, et al. Prediction of pulmonary function after lung lobectomy by subsegments counting, computed tomography, single photon emission computed tomography and computed tomography: a comparative study. Eur J Cardiothorac Surg. 2009;35:408-13.

25. Ohno Y, Koyama H, Nogami M, Takenaka D, Matsumoto S, Yoshimura M, et al. Postoperative lung function in lung cancer patients: comparative analysis of predictive capability of MRI, CT, and SPECT. AJR Am J Roentgenol. 2007; 189:400-8.

\section{Submit your next manuscript to BioMed Central} and we will help you at every step:

- We accept pre-submission inquiries

- Our selector tool helps you to find the most relevant journal

- We provide round the clock customer support

- Convenient online submission

- Thorough peer review

- Inclusion in PubMed and all major indexing services

- Maximum visibility for your research

Submit your manuscript at www.biomedcentral.com/submit

) Biomed Central 